\title{
Infrared Signal Detection by Upconversion Technique
}

\author{
Teh-Hwa Wong ${ }^{1 *}$, Jirong $\mathbf{Y u}^{2}$, Yingxin Bai ${ }^{1}$ and William Johnson ${ }^{3}$ \\ ${ }^{1}$ Science Applications International Corporation, One Enterprise Parkway, Suite 300, Hampton, VA 23666-5845 \\ ${ }^{2}$ NASA Langley Research Center, MS. 468, Hampton, VA 23681 \\ ${ }^{3}$ Montana State University, Department of Physics, EPS Room 264, Bozeman, Montana 59717 \\ *teh-hwa.wong@ssaihq.com
}

\begin{abstract}
We demonstrated up-conversion assisted detection of a $2.05-\mu \mathrm{m}$ signal by using a bulk periodically poled Lithium niobate crystal. The $94 \%$ intrinsic up-conversion efficiency and $22.58 \%$ overall detection efficiency at $\mathrm{pW}$ level of $2.05-\mu \mathrm{m}$ was achieved.

OCIS codes: (040.3060) Infrared; (190.4410) Nonlinear optics; (190.7220) Upconversion.
\end{abstract}

\section{Introduction}

Laser operating at 2-micron wavelength offers many measurement capabilities in remote sensing applications. The ground testing and flight testing of a 2-micron Doppler Aerosol Wind Lidar system has been demonstrated in the early years of development. The wavelength of this laser also matches one absorption band of $\mathrm{CO}_{2}$, which means this lidar system can be used to monitor the concentration of $\mathrm{CO}_{2}$ in the atmosphere. Currently, the detector in 2 micron lidar system is a Hamamatsu long wavelength type InGaAs PIN detector with low efficiency in the 2 micron region. It is not comparable to the high detection efficiency and low dark current of Si detector in the visible region. Our approach is to develop a Lithium niobate (PPLN) based frequency up-conversion device to efficiently convert the $2.055 \mu \mathrm{m}$ signal into $0.7 \mu \mathrm{m}$. Then the $0.7 \mu \mathrm{m}$ signal can be detected by a high efficiency Si detector.

Most previous work of sum frequency generation has focused on the communication wavelength $1.55 \mu \mathrm{m}$ [1]. The up-conversion efficiency in this near-IR region can achieve $74 \%$ to $99 \%$. Farther into the mid-IR region, the low transmission of the mid-IR inside PPLN and the blackbody radiation in the same spatial region cause the low up-conversion efficiency [2,3]. Beside the bulk PPLN, there are some research works on using PPLN waveguide. Ideally the up-conversion efficiency can reach $100 \%$ in a waveguide PPLN. However, there are also limitations on the detection efficiency using a waveguide PPLN. Shentu et.al. studied the up-conversion of $1.95 \mu \mathrm{m}$ [4] by using a waveguide. The intrinsic up-conversion efficiency was $99.6 \%$, but, the inefficient coupling lowered the detection efficiency down to $10 \%$.

\section{Experimental Setup}

The schematic of the experimental setup for intra-cavity up-conversion is shown in Fig. 1. M3 and M4 are concave mirrors each with a radius-of-curvature of $150 \mathrm{~mm}$. The $50 \mathrm{~mm}$ long and $5 \mathrm{~mol} \% \mathrm{MgO}$-doped PPLN crystal is located inside of a $52.3{ }^{\circ} \mathrm{C}$ Teflon oven, which is mounted on top of a multi-axis stage. A CW $0.808 \mu \mathrm{m}$ diode laser is used to pump a $10 \mathrm{~mm}$ long $1 \%$ doped Nd:YAG rod in the cavity to generate unidirectionally $1.064 \mu \mathrm{m}$ beam. Two lenses both with $150 \mathrm{~mm}$ focus length were used to focus $2-\mu \mathrm{m}$ DFB laser beam into the cavity.

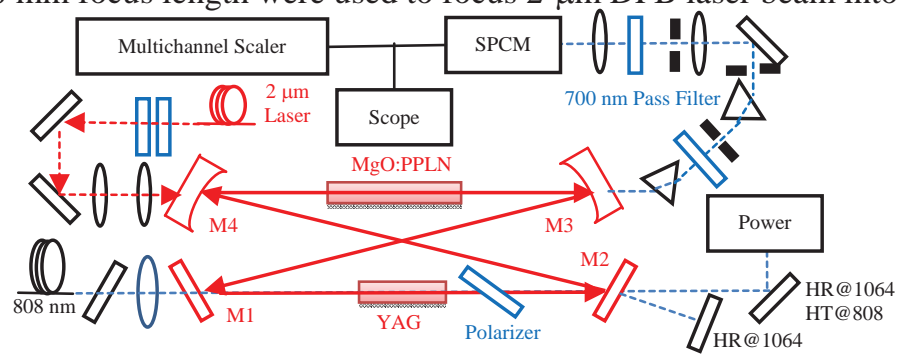

Fig. 1. Schematic of the up-conversion experimental setup

\section{Results and Discussions}

When the power of the source laser is in $\mathrm{mW}$ range, the $0.7 \mu \mathrm{m}$ signal will also be in the $\mathrm{mW}$ range and can be easily detected by a power meter. The power dependence of the $0.7 \mu \mathrm{m}$ signal on the upconverting $2 \mu \mathrm{m}$ signal was studied at constant $7.5 \mathrm{~W}$ pump laser power. The result is plotted on a log-log graph and shown in Fig. 2(a). The slope of the linear fitting is $0.983 \pm 0.029$ which indicates that the $0.7 \mu \mathrm{m}$ signal strength is linearly dependent on the 
$2 \mu \mathrm{m}$ laser power. Fig. 2(b) shows the results of pump power dependance and the up-conversion efficiency for a fixed $2 \mu \mathrm{m}$ signal at $1.308 \mathrm{~mW}$. The solid squares on the graph are the overall system detection efficiency, and solid circles are the data after correction of system transmission. The intrinsic up-conversion efficiency of PPLN can be as high as $93 \%$ at $34 \mathrm{~W}$ pump laser power. The overall detection efficiency is $60 \%$.

A single photon counting module SPCM-AQRH-14 was used to detect single photon signals, and the output of SPCM was sent to a Multichannel scaler/average. The $2 \mu \mathrm{m}$ laser output was $0.185 \mathrm{~mW}$ before it was attenuated with optical fiber couplers or IR Neutral Density (ND) filters. The SPCM we used has higher than normal dark count rates due to its age. The $2 \mu \mathrm{m}$ laser signal alone did not add to measured count rates. But, when the $0.808 \mu \mathrm{m}$ laser was turned on, the background level increased by 594 counts/sec. This noise was verified to be from the 0.808 $\mu \mathrm{m}$ pump laser and not from the $1064 \mathrm{~nm}$ light. The $0.7 \mu \mathrm{m}$ signal dependence on $2 \mu \mathrm{m}$ laser power was also characterized at this extremely low $2 \mu \mathrm{m}$ power $(\mathrm{pW})$. Figure 2(c) shows the relationship of $0.7 \mu \mathrm{m}$ signal at various $2 \mu \mathrm{m}$ signals by arranging the IR ND filters. The 0.963 slope in the log-log plot indicates the linear dependence of $0.7 \mu \mathrm{m}$ signal on $\mathrm{pW}$ range 2-micron power. Fig. 2(d) shows the power dependence of the $0.7 \mu \mathrm{m}$ signal on YAG laser power at fixed $2 \mu \mathrm{m}$ signal; saturation is observed at $9 \mathrm{~W}$ YAG laser power.
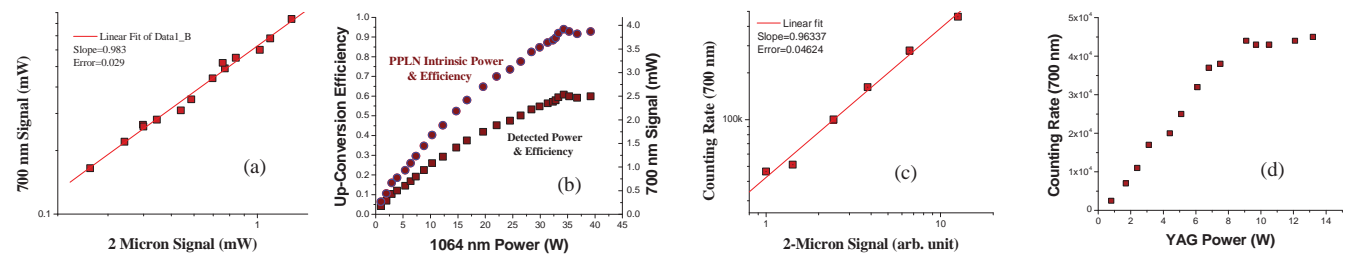

Fig. 2. (a) $2 \mu \mathrm{m}$ laser power dependence at $\mathrm{mW}$ level of $2 \mu \mathrm{m}$ power, (b) Pump laser power dependence at $\mathrm{mW}$ level of $2 \mu \mathrm{m}$ power,

(c) $2 \mu \mathrm{m}$ laser power dependence at $\mathrm{pW}$ level of $2 \mu \mathrm{m}$ power, (d) Pump laser power dependence at $\mathrm{pW}$ level of $2 \mu \mathrm{m}$ power

The total detection efficiency of $0.7 \mu \mathrm{m}$ of the SPCM system (also including prisms, mirrors, $0.7 \mu \mathrm{m}$ pass filters \& QE of SPCM) will be $24.02 \%$. The initial 2-micron power is $0.1855 \mathrm{~mW}$ and attenuated by a factor of $1.27 \times 10^{-9}$ by IR ND filters. Thus, the incoming 2-micron photons are at $2.44 \times 10^{5}$ photons per second. The detected counting rate of $0.7 \mu \mathrm{m}$ is 55,000 photons per second on the counter. So the intrinsic up-conversion efficiency is $94 \%$ in the single photon counting region, with an overall detection efficiency of $22.58 \%$.

\section{Conclusion}

We have demonstrated up-conversion detection of a 2- $\mu \mathrm{m}$ signal. High intrinsic conversion efficiency $\eta=93$ to $94 \%$ of bulk PPLN was achieved for $\mathrm{mW}$ level and $\mathrm{pW}$ level of the source laser and the overall detection efficiencies are $59.97 \%$ and $22.58 \%$ respectively. It is still be limited by propagation losses of the optics, especially the $0.7 \mu \mathrm{m}$ laser line pass filter. It was verified that $0.808 \mu \mathrm{m}$ is the source of noise in photon counting. This wavelength is so close to $0.7 \mu \mathrm{m}$ that it is not easy to separate them completely. Because of this difficulty, two $0.7 \mu \mathrm{m}$ laser line pass filters were used to block the $0.808 \mu \mathrm{m}$ light. But these attenuate the $0.7 \mu \mathrm{m}$ signal by $50 \%$. Overall efficiency could be improved by externally pumping with a $1.06 \mu \mathrm{m}$ laser directly.

The linearity of the $0.7 \mu \mathrm{m}$ signal on the source laser ( 2 micron) was demonstrated at $\mathrm{mW}$ and $\mathrm{pW}$ levels; showing that the $0.7 \mu \mathrm{m}$ signal size can be directly connected to the $\mathrm{CO}_{2}$ concentration over a wide source laser power range. Up-conversion detection by using bulk PPLN is a promising technique to extend the use of welldeveloped silicon detectors in to remote sensing applications.

This work was supported by NASA LaRC IRAD Program.

\section{References and Links:}

[1] Marius A. Albota and FrancoN. C. Wong. "Efficient single-photon counting at $1.55 \mu \mathrm{m}$ by means of frequency upconversion," Optics Letters, 29(13), 1449-1451 (2004)

[2] Xiaorong Gu, Kun Huang, Haifeng Pan, E Wu and Heping Zeng, "Efficient mid-infrared single-photon frequency upconversion detection with ultra-low background counts," Laser Physics Letters 10, 055401 (2013)

[3] Guilherme Temporao, Sebastien Tanzilli, Hugo Zbinden, Nicolas Gisin, Thierry Aellen, Marcella Giovannini and Jerome Faist, "Mid-infrared single-photon counting," Optics Letters, 31(8), 1094-1096 (2006)

[4] Guo-Liang Shentu, Xiu-Xiu Xia, Qi-Chao Sun, Jason S. Pelc, M. M. Fejer, Qiang Zhang and Jian-Wei Pan, "Upconversion detection near 2 $\mu \mathrm{m}$ at the single photon level," Optics Letters, 38(23), 4985-4987 (2013) 